\title{
Alkali Attack on Cation-Exchange Membranes with Polyvinyl Chloride Backing and Binder: Comparison with Anion-Exchange Membranes
}

\author{
Shoichi Doi ${ }^{1,2}$, Nobuya Takumi ${ }^{2}$, Yuriko Kakihana ${ }^{2,3}$ and Mitsuru Higa ${ }^{2,3, *}$ \\ 1 Astom Corporation, 1-1 Mikagecho, Syunan, Yamaguchi 745-8648, Japan; s.doi@astom-corp.jp \\ 2 Graduate School of Sciences and Technology for Innovation, Yamaguchi University, 2-16-1 Tokiwadai, Ube, \\ Yamaguchi 755-8611, Japan; a064vfu@yamaguchi-u.ac.jp (N.T.); kakihana@yamaguchi-u.ac.jp (Y.K.) \\ 3 Blue Energy Center for SGE Technology (BEST), 2-16-1 Tokiwadai, Ube, Yamaguchi 755-8611, Japan \\ * Correspondence: mhiga@yamaguchi-u.ac.jp; Tel.: +81-836-85-9203
}

Received: 25 August 2020; Accepted: 9 September 2020; Published: 11 September 2020

\begin{abstract}
Systematic alkali immersion tests of cation-exchange membranes (CEM) with polyvinyl chloride (PVC) as their backing and binder were conducted to compare that of an Anion-exchange membrane (AEM) with the same PVC materials to investigate the mechanism of dehydrochlorination. In the immersion tests, originally colorless and transparent AEM turned violet, and chemical structure analysis showed that polyene was produced by the dehydrochlorination reaction. However, the CEM did not change in color, chemical structure or membrane properties during the test with less than $1 \mathrm{M}$ alkali solutions. According to the Donnan equilibrium theory and the experiments using CEM and AEM, the hydroxide ion concentration in the CEM was much lower than that in the AEM under the same conditions. However, when the alkali immersion test was performed using the CEM under more severe conditions $\left(6 \mathrm{M}\right.$ for $168 \mathrm{~h}$ at $\left.40{ }^{\circ} \mathrm{C}\right)$, there was a slight change in the color and chemical structure of the CEM, clearly indicating that not only AEMs, but also CEMs with PVC matrixes were deteriorated by alkali, depending on the conditions.
\end{abstract}

Keywords: cation-exchange membrane; anion-exchange membrane; degradation; alkaline; polyvinyl chloride; cleaning in place; dehydrochlorination

\section{Introduction}

The electrodialysis (ED) processes using hydrocarbon ion-exchange membranes (IEMs) have been used for almost half a century to produce salts from seawater, desalination from brackish water or food and beverages, and valuable salt recovery from wastewater treatment in the chemical industry. It has also been widely applied to various types of industries [1]. While it can be considered as a mature technology, the research and development of the ED process has still been active. For example, ED applications that use monovalent ion selective membranes, such as desalting from brackish water [2], recovery of sodium formate from waste water [3], and zinc recovery from wastewater using ED enhanced with chelating agents [4], have been reported. In addition, research on reverse electrodialysis, in which salinity gradient energy is converted to electricity using IEMs, has been actively conducted [5-9].

In industrial ED processes, alkaline cleaning processes, such as cleaning in place, are frequently employed to control anion-exchange membrane (AEM) contamination to ensure stable and reliable operation over long periods of time. One of the authors who works for the ASTOM corporation observed a returned membrane from a commercial plant, as shown in Figure 1. They were Neosepta ${ }^{\circledR}$ AMX (AEM) and CMX (CEM), which were used in ED desalination of leachate for eight-years. Original AMX was colorless and transparent and CMX was dark yellow. However, after eight-years operation, 
the color of the upper side of the returned AMX irreversibly changed to dark violet, but there was no color change in the returned CMX. We would like to clarify the difference in the alkali deterioration between the AEM and the CEM.

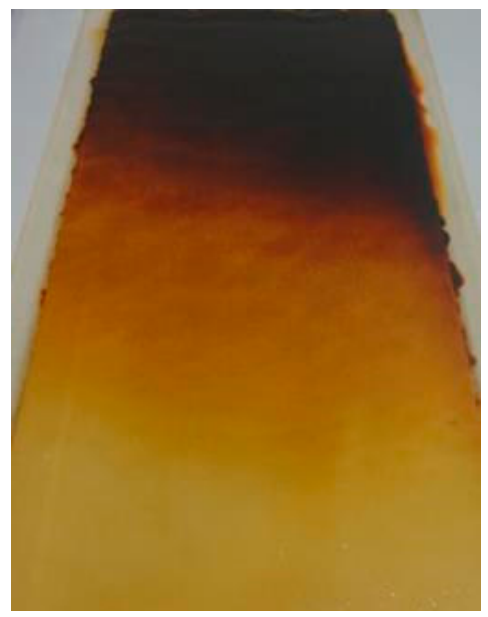

(a) AMX

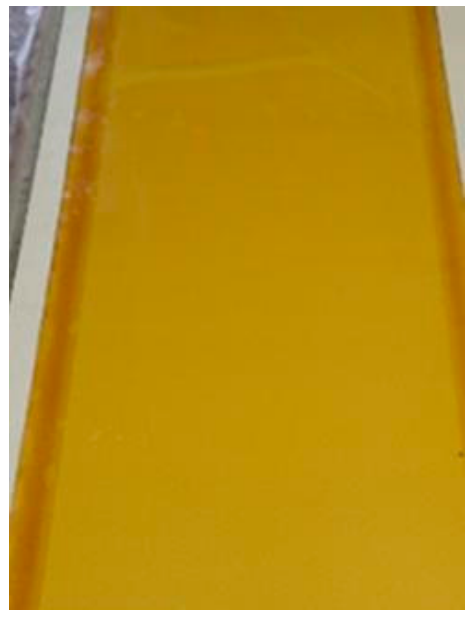

(b) $\mathrm{CMX}$

Figure 1. Neosepta ${ }^{\circledR} A M X$ and CMX returned from the electrodialysis (ED) desalination plant of leachate for 8 years with appropriate cleaning-in-place (CIP) treatments; (a) AMX; (b) CMX.

Grande et al. focused on the degradation of IEMs with respect to the commercial food and beverage industries and compared the degradation behavior of homogeneous and heterogeneous AEMs and CEMs [10-15]. The degradation of AEMs was deeply discussed and was based on the electrochemical and mechanical properties and the analytical data using Scanning Electron Microscope (SEM), Energy-Dispersive X-ray Spectroscopy (EDX) and Fourier Transform Infrared Spectrometer (FTIR). There have been some reports on the degradation of CEMs: the CEM operating in an organic acid commercial plant was analyzed in the same manner as the AEM, and a decrease in tensile strength and an increase in electrical resistance were observed. The ion-exchange groups were lost and the surface was hydrophobized, but the reason for the phenomena has not been clarified $[10,11,13]$. They carried out AEM and CEM immersion tests in a sodium hypochlorite solution. While quaternary ammonium groups were decomposed in AEMs, the sulfonic acid groups were not attacked in CEMs. It has also been reported that the Styrene-Di-vinyl benzene (St-DVB) crosslinked structure was eroded and became porous in both AEMs and CEMs [14].

In general, some homogeneous cation-exchange membranes (CEMs) and AEMs have been manufactured by the paste method using polyvinyl chloride (PVC) cloth as the backing [16,17]. Vasquez et al. subjected the AEM and CEM, containing PVC as the backing and binder, to $2 \mathrm{M} \mathrm{NaOH}$ immersion tests and a $0.1 \mathrm{M} \mathrm{NaOH} / 0.1 \mathrm{M} \mathrm{HCl}$ cycle test. They showed that the quaternary ammonium salt in the AEM membrane acts as a catalyst, and dehydrochlorination of PVC with hydroxide ions occurs, which results in the formation of a polyene sequence. No change in the stress-strain curve, obtained during tensile tests, was confirmed for the CEM, and other physical properties evaluations and chemical structure analyzes of the CEM were not performed [15].

To the author's knowledge, for the CEMs, there have been no reports of systematic discussion of the correlation between alkaline immersion conditions and changes in the chemical structure and properties after the immersion test.

This study aims to investigate the influence of alkaline attack on the performance of commercial CEMs containing PVC as the backing and binder, and to gain some insight into the alkali degradation mechanism of CEMs and AEMs with PVC materials. To this end, the hydroxyl ion distributions inside the AEM and CEM after immersion in various concentrations of alkali solutions were measured. Subsequently, alkaline immersion tests of the CEMs were systematically conducted using the same 
procedure as reported for AEMs previously [18]. Further, the precursors of CEMs and AEMs were also immersed in alkali for a control. The chemical structure analyses (FTIR and X-ray Fluorescence (XRF)) and membrane properties of CEMs were also examined in order to compare them with those of AEMs.

\section{Materials and Methods}

\subsection{Sample Membrane}

Neosepta ${ }^{\circledR}$ CMX was used as the commercial homogeneous CEM, and Neosepta ${ }^{\circledR}$ AMX was used as the homogeneous AEM (both supplied by ASTOM Corporation of Tokyo, Japan) in this study. CMX and AMX are both standard grades for industrial use, and their basic properties are listed in Table 1. The precursors of CEM and AEM were also supplied by ASTOM Corporation (Tokyo, Japan). Both CMX and AMX were produced by the paste method using the respective precursors and contain PVC as the backing and binder [16,17].

Table 1. Materials and properties of CMX and AMX (PVC: polyvinyl chloride).

\begin{tabular}{ccccccc}
\hline & Backing & Binder & $\begin{array}{c}\text { Thickness } \\
(\mathbf{m m})\end{array}$ & $\begin{array}{c}\text { Ion-Exchange Capacity } \\
\text { (meq./g-Dry-Membrane) }\end{array}$ & $\begin{array}{c}\text { Water Content } \\
\text { (\%) }\end{array}$ & $\begin{array}{c}\text { Fixed Charge Density } \\
\text { (meq./g-Water) }\end{array}$ \\
\hline CMX & PVC & PVC & 0.169 & 1.73 & 28.6 & 6.0 \\
\hline AMX & PVC & PVC & 0.143 & 1.47 & 20.9 & 7.0 \\
\hline
\end{tabular}

\subsection{Estimation of Hydroxyl Ion Concentration in CMX and AMX}

All the reagents were obtained from FUJIFILM Wako Pure Chemical Corporation (Osaka, Japan) and used without further purification. The electrical conductivity of the de-ionized water used in this study was approximately $5 \mu \mathrm{S} / \mathrm{cm}$. CMX and AMX were immersed in $0.01 \mathrm{M}, 0.1 \mathrm{M}, 1 \mathrm{M}$ and $6 \mathrm{M} \mathrm{NaOH}$ solutions, and the hydroxyl ion concentrations in the membranes were determined experimentally. The $6 \mathrm{M} \mathrm{NaOH}$ concentration was almost the same as those for the fixed ionic groups of the two membranes. Firstly, the test pieces of the membranes were soaked in a $0.5 \mathrm{M} \mathrm{NaCl}$ solution to exchange the counter ion of $\mathrm{CMX}$ with $\mathrm{Na}^{+}$ions and that of $\mathrm{AMX}$ with $\mathrm{Cl}^{-}$ions completely. The test pieces were then immersed in $0.01 \mathrm{M}, 0.1 \mathrm{M}, 1 \mathrm{M}$, and $6 \mathrm{M} \mathrm{NaOH}$ solutions for $1 \mathrm{~h}$ at $25^{\circ} \mathrm{C}$. They were removed from the solution, rinsed with deionized water, and the surface water on the membranes was removed with a wiper. Each sample was then immersed in a $0.5 \mathrm{M} \mathrm{NaCl}$ solution with a volume of $V_{o}$ for $30 \mathrm{~min}$. After retrieving each test piece, the change in $\mathrm{pH}$ in the solution was measured using a $\mathrm{pH}$ meter D-51 (HORIBA, Kyoto, Japan) to calculate the hydroxyl ion concentration in the solution $C_{s}$. The test pieces were weighed at a wet state and were dried at $60{ }^{\circ} \mathrm{C}$ using a vacuum oven for over $24 \mathrm{~h}$ to measure the dry weight. The water content of the sample $V_{m}$ was calculated by subtracting the dry weight from the wet weight of the test piece. The $\mathrm{OH}$ (hydroxyl ion) concentration in the test piece $C_{m}$ was calculated using the following equation:

$$
C_{m}=\frac{C_{s} V_{o}}{V_{m}}
$$

\subsection{Alkaline Immersion Test}

\subsubsection{Low $\mathrm{OH}$ Concentration Test}

An alkaline immersion test of CMX was conducted using the same methods as those used for AMX, which was described in previous papers [18,19]. CMX and AMX are recommended to be used at a temperature of under $40{ }^{\circ} \mathrm{C}$, according to the supplier's instructions. However, in a previous study, besides conducting the experiment at the recommended temperature of $40{ }^{\circ} \mathrm{C}$, the authors also conducted an immersion test of $\mathrm{AMX}$ at $60^{\circ} \mathrm{C}$ and $80^{\circ} \mathrm{C}$ as an accelerated test. It was observed during the test that the water content of AMX increased, and its electrical resistance decreased, even when it was immersed in alkali-free water. It will be due to the fact that the effects of the residual stress in the cross-linked structure formed during the production being relieved by the immersion tests at high 
temperatures were superimposed [18]. Therefore, in this study, a CMX immersion test was performed at only $40{ }^{\circ} \mathrm{C}$ to obtain the test pieces for subsequent chemical analysis. The alkali concentrations of the low $\mathrm{OH}$ concentration test were $0.01 \mathrm{M}, 0.1 \mathrm{M}$, and $1 \mathrm{M} \mathrm{NaOH}$. A test was also performed using deionized water to serve as a control. The immersing time periods were $3 \mathrm{~h}, 24 \mathrm{~h}$ ( 1 day), and $168 \mathrm{~h}$ (1 week).

\subsubsection{High $\mathrm{OH}$ Concentration Test}

According to the Donnan exclusion, the concentration of hydroxyl ions in a CEM gel phase is much lower than that in the external solution under the conditions of the low concentration tests. According to the microheterogeneous model [20], the concentration of hydroxyl ions in the central part of the mesopores of the CMX and AMX membranes are approximately the same and equal to the concentration of the external solution. However, the proportion of such a solution in both membranes is relatively small-it is no more than 0.1 [21]. However, it was predicted that the $\mathrm{OH}$ concentration in the CEM gel phase was almost equal to that in the external solution and almost the same as that in the AEM, when the concentration in the external solution gets closer to the fixed charge density of the CEM.

The purpose of the experiments in this section was to confirm the difference in the effect of alkali degradation on the chemical structure variation between IEMs containing the quaternary ammonium group and sulfonic acid group, when the concentration of hydroxyl ions in the two membranes was almost similar. Hence, the two membranes were immersed in $\mathrm{NaOH}$ solutions with a high concentration $(6 \mathrm{M})$, which was almost equal to the fixed charge density of CMX and AMX.

The AMX and CMX used in this study were produced using the paste method $[16,17,22]$. In this method, the PVC backing cloth is dipped into a paste, which is a mixture of monomer, PVC binder, and initiator. The paste material was polymerized by heating in order to form the precursor for each membrane. Then, sulfonic acid groups were introduced into CMX, while the quaternary ammonium group was introduced into AMX. To confirm the effect of ion-exchange groups, the respective precursors were also immersed in a $6 \mathrm{M} \mathrm{NaOH}$ solution at $40^{\circ} \mathrm{C}$. The immersing time periods were $3 \mathrm{~h}, 24 \mathrm{~h}$ (1 day), and $168 \mathrm{~h}$ (1 week).

\subsection{Chemical Analysis}

The FTIR spectrum and XRF intensity of the Ka line of chlorine were measured for the samples subjected to alkali immersing tests. The infrared absorption spectra were measured by the Bruker Optics LUMOS (Bruker Japan, Yokohama, Japan) and microscopic attenuated total reflection (ATR) method. All the samples subjected to FTIR were immersed in a $0.5 \mathrm{M} \mathrm{NaCl}$ aqueous solution, so that the counter ions of CMX and AMX could be $\mathrm{Na}$ ions and $\mathrm{Cl}$ ions, respectively. Vacuum-drying was then conducted at $40{ }^{\circ} \mathrm{C}$ or less for over $4 \mathrm{~h}$.

The XRF intensity of the Ka line of chlorine was measured by ZSX Primus II (Rigaku, Tokyo, Japan). All the samples were subjected to vacuum-drying at $40{ }^{\circ} \mathrm{C}$ or less for $4 \mathrm{~h}$ or more, and then they were immersed in a $0.2 \mathrm{M}$ aqueous solution of $\mathrm{NaNO}_{3}$, so that the counter ions of $\mathrm{CMX}$ and AMX could be $\mathrm{Na}$ ions and $\mathrm{NO}_{3}$ ions, respectively. The detailed procedures of the experiments were provided in previous papers [18,19].

\subsection{Characterization of Membrane Properties}

The properties of the membranes immersed in low $\mathrm{OH}$ concentration tests were characterized. The samples were immersed in a $0.5 \mathrm{M} \mathrm{NaCl}$ aqueous solution, so that the counter ions of CMX and $\mathrm{AMX}$ were $\mathrm{Na}$ ions and $\mathrm{Cl}$ ions, respectively. Mechanical and electrical properties (Young's modulus, water content, ion-exchange capacity (IEC), electrical resistance and hydroxyl ion rejection) of CMX before and after the low $\mathrm{OH}$ concentration alkaline immersion tests were characterized, as described in previous papers [18,19]. 
The hydroxyl ion rejection of the test piece was measured using a craft-made acrylic plastic cell comprising two chambers with a Pt electrode. A $0.5 \mathrm{M} \mathrm{NaOH}$ solution and a $3 \mathrm{M} \mathrm{NaOH}$ solution were poured into the anode cell and the cathode cell, respectively. Each solution was stirred with a magnetic stirrer and maintained at $25{ }^{\circ} \mathrm{C}$. A current density of $10 \mathrm{~A} / \mathrm{dm}^{2}$ was applied between the electrodes for $3600 \mathrm{~s}$. The molar number of hydroxyl ions in the cathode cell before the test $\left(M_{1}\right)$ and after the test $\left(M_{2}\right)$ was determined by titration with a $0.05 \mathrm{M} \mathrm{H}_{2} \mathrm{SO}_{4}$ solution to obtain the hydroxyl ion rejection $\left(P_{\mathrm{OH}}\right)$ according to the following equation:

$$
P_{\mathrm{OH}}=\frac{M_{2}}{M_{1}}
$$

Similarly, the membrane properties before the alkali immersion test was compared with those after the test by calculating the normalized property ratio $\left(P R_{x}\right)$ as follows:

$$
P R_{x}=\frac{P_{x}^{a f t e r}}{P_{x}^{\text {before }}}
$$

where $P_{x}^{a f t e r}$ and $P_{x}^{\text {before }}$ denote the membrane properties (e.g., $\mathrm{x}=$ Y: Young's modulus, W: water content, IEC: ion-exchange capacity, ER: electrical resistance, $\mathrm{OH}$ : hydroxyl ion rejection, and $\mathrm{CO}$ : co-ion rejection) after and before the alkali immersion test, respectively.

\section{Results and Discussion}

\subsection{Measurement of Alkali Concentration in CMX and AMX}

When the IEMs were immersed in a $\mathrm{NaOH}$ solution with a concentration of $\mathrm{C}_{\mathrm{NaOH}}$, the theoretical value of the hydroxyl ion concentration in the IEMs at an equilibrium state $\bar{C}_{O H}$ was calculated from the following equations. For simplicity, we assumed that the standard chemical potential difference and activity coefficient of ions in the solution were equal to those of the membrane [23].

$$
\overline{\mathrm{C}}_{\mathrm{OH}}=\mathrm{C}_{\mathrm{NaOH}} K_{\text {don }}
$$

where $K_{d o n}$ is the Donnan equilibrium constant, which is calculated from the electroneutrality condition in the membrane and equation of the Donnan theory [23] as follows:

$$
K_{\text {don }}=\frac{z_{x} C_{x}}{2 C_{\mathrm{NaOH}}}+\sqrt{\left(\frac{z_{x} C_{x}}{2 C_{\mathrm{NaOH}}}\right)^{2}+1}
$$

where $z_{x}$ and $C_{x}$ are the valence and concentration of the membrane-fixed charge $\left(z_{x}\right.$ is 1 for an AEM and -1 for a CEM).

Hydroxyl ion concentrations in CMX and AMX were estimated using these equations. In the case of CMX, $C_{x}$ was calculated as $6 \mathrm{M}$ using IEC and W (listed in Table 1), so that the theoretical curve was calculated by substituting $C_{x}=6 \mathrm{M}$ into Equation (5). The theoretical calculations, as well as the experimental values obtained, are shown in Figure 2. The theoretical curve of CMX indicates that the concentration of hydroxyl ions as the co-ions was much lower than that of the external solution. For example, when CMX was immersed in a $0.01 \mathrm{M} \mathrm{NaOH}$ solution, the hydroxyl ion concentration in the CMX membrane was $1.7 \times 10^{-5} \mathrm{M}$, which was almost $1 / 1000$ of the concentration of the external solution. While the concentration in the membrane increases as much as that of the external solution, the concentration in CMX was observed to be $0.16 \mathrm{M}$, even when it was immersed in a $1 \mathrm{M} \mathrm{NaOH}$ solution, which was approximately $1 / 6$ of the external solution concentration. In contrast, when CMX was immersed in a $6 \mathrm{M} \mathrm{NaOH}$ solution, the concentration was observed to be $3.7 \mathrm{M}$, which was approximately $60 \%$ of the external solution concentration. 


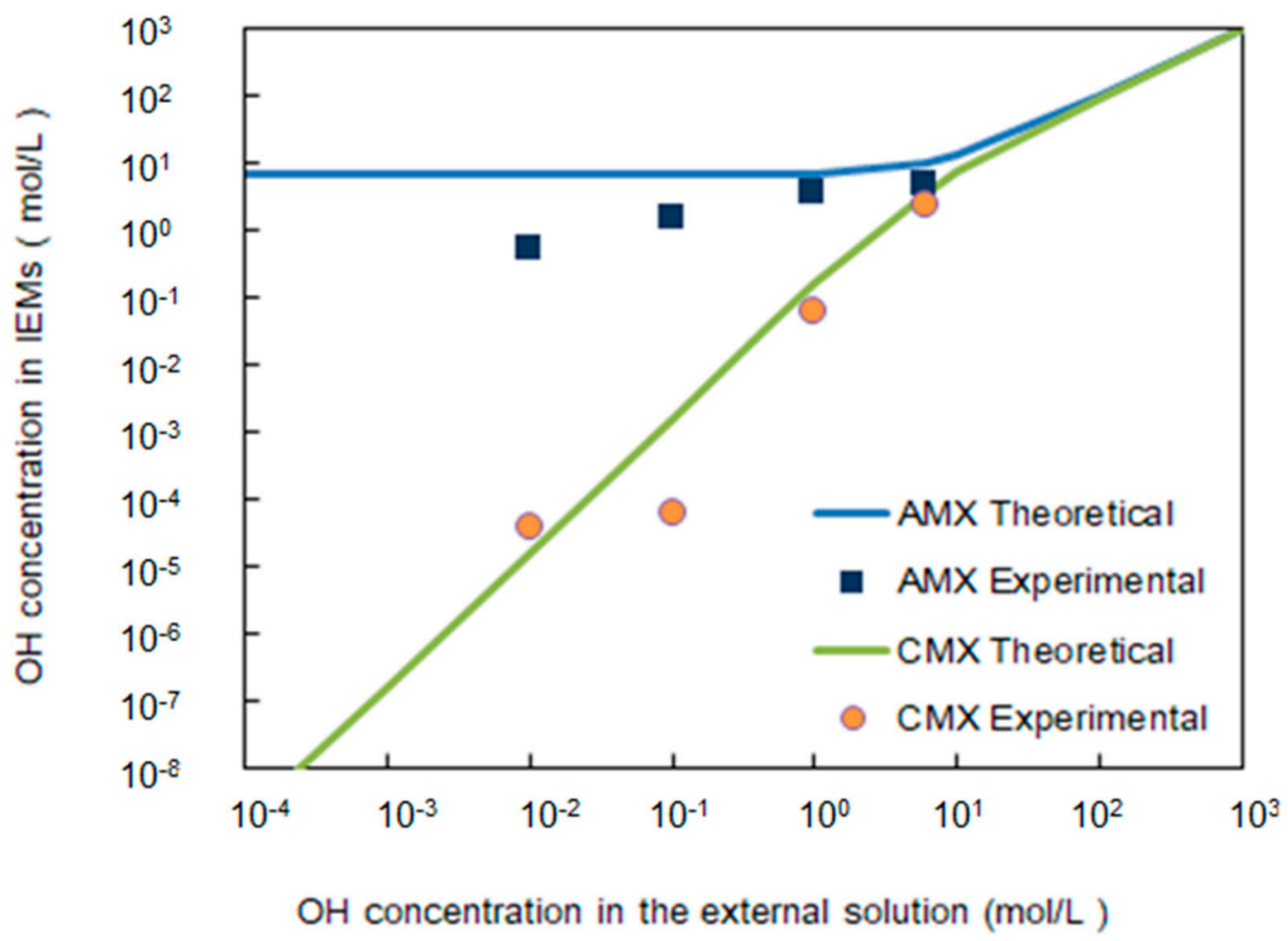

Figure 2. Theoretical and experimental values of hydroxyl ion concentration in the ion-exchange membranes (IEMs) as a function of the external solution concentration.

In the experiments involving $0.01 \mathrm{M}, 1 \mathrm{M}$, and $6 \mathrm{M} \mathrm{NaOH}$ as the external solution, the $\mathrm{OH}$ concentration in CMX was estimated at $3.9 \times 10^{-5} \mathrm{M}, 0.062 \mathrm{M}$, and $2.5 \mathrm{M}$, respectively. Each of these experimental observations almost agreed quantitatively with those from the theoretical curve shown in Figure 2. This indicates that the concentration of the co-ions, such as the hydroxyl ions in a CEM, can be estimated quantitatively by substituting the value of fixed charge density into the equation based on the Donnan theory for a wide range of concentrations. The theoretical calculations, as well as the experiments, indicate that the concentration of the co-ions in the CEM was much lower than that of the external solution, when the CEM was immersed in solutions with low $\mathrm{OH}$ concentrations.

In the case of AMX, $C_{x}$ was calculated to be $7 \mathrm{M}$ using IEC and $\mathrm{W}$ shown in Table 1 . Therefore, the theoretical curve was obtained by substituting $C_{x}=7 \mathrm{M}$ into Equation (5). The theoretical values and experimental results obtained at $25^{\circ} \mathrm{C}$ are also shown in Figure 2. In contrast to CMX, the theoretical calculations in the case of immersing AMX in the $\mathrm{NaOH}$ solution with low concentrations indicate that the concentration of the hydroxyl ions as the counter ions of AMX were approximately equal to $7 \mathrm{M}$ of fixed charge density, regardless of the external solution. When the concentration of the external solution was higher than the fixed charge density, the counter ion concentration in AMX increased with an increase in the external solution concentration and was approximately equal to the external solution concentration. While some deviations were observed between the experimental values and calculations in the case of immersing the AEM in lower $\mathrm{NaOH}$ concentrations, the experiments almost agreed quantitatively with the calculations. One of the reasons for this deviation could be that a complete ion exchange between the counter ion of fixed charge and hydroxyl ions in the solution did not occur, when the test piece was immersed in a solution with a low concentration of hydroxyl ions. The test piece was immersed in the $\mathrm{NaOH}$ solution for only $1 \mathrm{~h}$ to minimize the effects of chemical degradation due to hydroxyl ions. Another possible reason could be that the dehydrochlorination reaction during the immersion test generated hydrochloric acid. The neutralization reaction between the generated hydrochloric acid and hydroxyl ions in the test pieces consumed the hydroxyl ions. Therefore, the $\mathrm{OH}$ concentration inside the test pieces were lower than that obtained from the calculations. 
Figures 3 and 4 show photographs of CMX and AMX test pieces after immersion in various solutions of $\mathrm{NaOH}$ concentrations, respectively. While no color change was observed in all the CMX test pieces, the color of the AMX test pieces changed from transparent to light yellow, orange, and dark violet with increasing $\mathrm{NaOH}$ concentrations. This indicates that PVC dehydrochlorination occurred in the test piece of AMX.

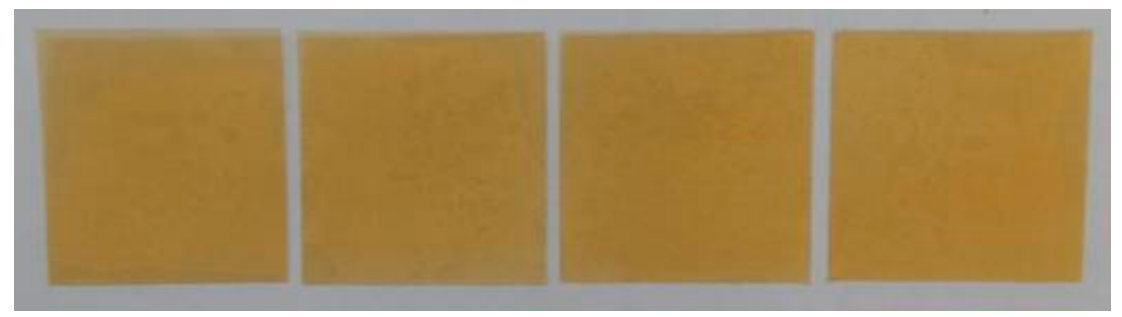
(a) $0.01 \mathrm{M}$
(b) $0.1 \mathrm{M}$
(c) $1 \mathrm{M}$
(d) $6 \mathrm{M}$

Figure 3. Color change of the CMX test pieces immersed in solutions of different $\mathrm{NaOH}$ concentrations for $1 \mathrm{~h}$ at $25^{\circ} \mathrm{C}$.

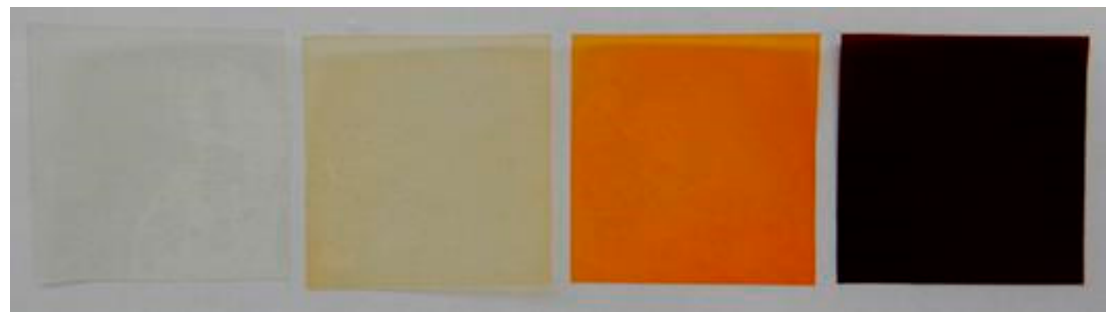
(a) $0.01 \mathrm{M}$
(b) $0.1 \mathrm{M}$
(c) $1 \mathrm{M}$
(d) $6 \mathrm{M}$

Figure 4. Color change of the AMX test pieces immersed in solutions of different $\mathrm{NaOH}$ concentrations for $1 \mathrm{~h}$ at $25^{\circ} \mathrm{C}$.

A comparison of the CMX and AMX test pieces is shown in Figures 3 and 4 and supported that the concentration of hydroxyl ions in CMX will vary considerably from that in AMX. The theoretical curve shown in Figure 2 indicates that, when AMX is immersed in the $0.01 \mathrm{M} \mathrm{NaOH}$ solution and $1 \mathrm{M}$ $\mathrm{NaOH}$ solution, its hydroxyl ion concentration is approximately $4 \times 10^{5}$ times and 40 times higher than that of CMX, respectively. As mentioned earlier, it is evident that the dehydrochlorination of CMX did not occur in the case of low $\mathrm{OH}$ concentration immersion tests, as the hydroxyl ion concentration in CMX is much lower than that in AMX under the same conditions.

In contrast, when the external solution concentration is almost equal to the fixed charge density, the hydroxyl ion concentration inside CMX is almost equal to that of AMX. Therefore, if the dehydrochlorination reaction is only dominated by the hydroxyl ion concentration during the immersion tests at higher concentrations, dehydrochlorination, similar to that in AMX, is expected to occur in CMX as well. However, even at a high concentration (6 M), no color change was observed in CMX during the immersion test, while AMX changed to dark violet. This phenomenon indicates that the dehydrochlorination reaction is difficult in CMX under these experimental conditions.

A hypothesis from prior reports stated that the quaternary ammonium groups facilitate the dehydrochlorination reaction of PVC [15]. The aforementioned results, shown in Figure 4, can aid in evaluating the validity of this hypothesis. A systematic alkaline immersion test of CMX was performed to confirm this hypothesis in the next section. 


\subsection{Systematic Alkaline Immersion Test (Low OH Concentration Test)}

\subsubsection{Color Change}

Figure 5a shows the color change of CMX test pieces with respect to various $\mathrm{NaOH}$ concentrations and immersion time periods at $40{ }^{\circ} \mathrm{C}$. No color change was observed in the CMX test pieces under all the test conditions. The membrane immersed in water for $168 \mathrm{~h}$ looked darker than the pristine, but the CMX membrane had color unevenness like the photo of $0.1 \mathrm{M}$ and $3 \mathrm{~h}$. Thus, we concluded that there was no change.

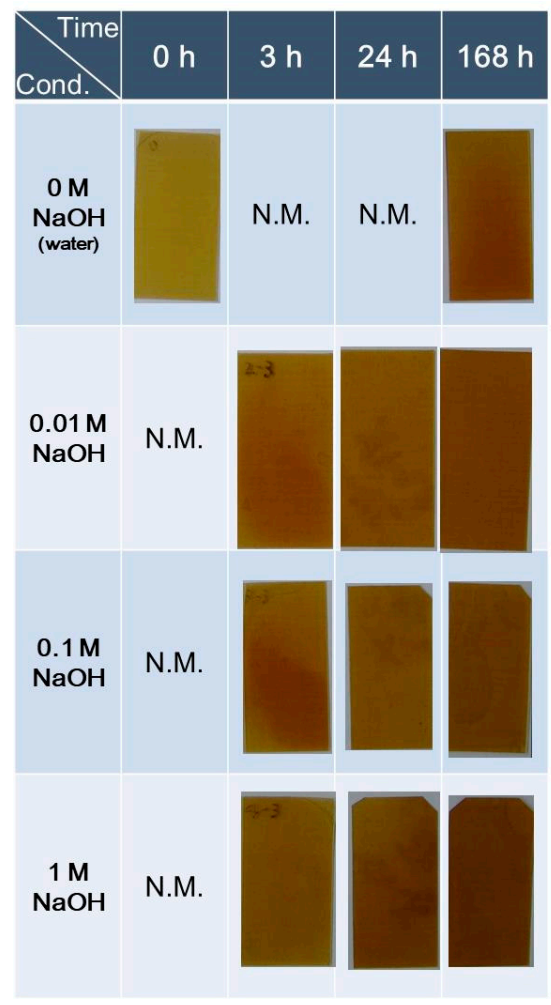

(a) CMX

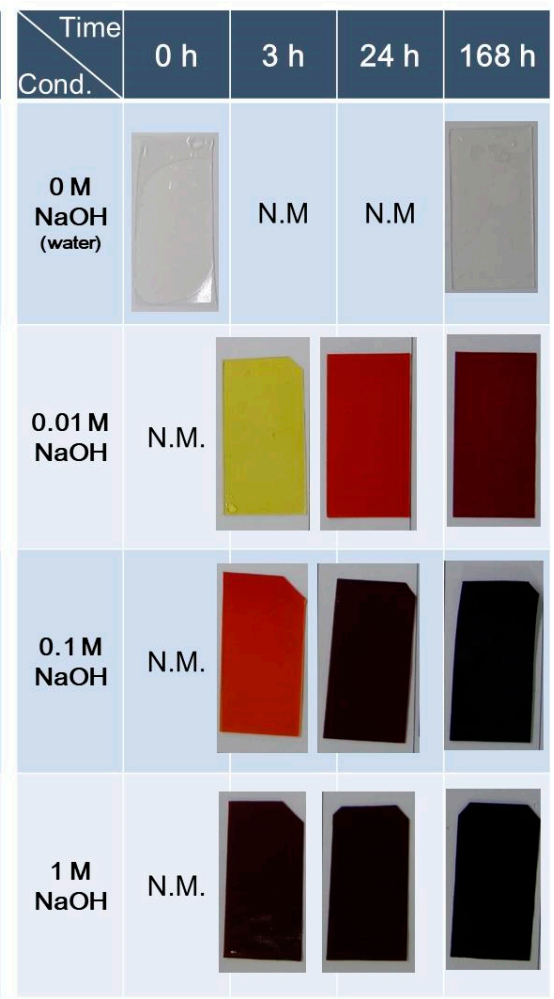

(b) AMX

Figure 5. Color change of test pieces with respect to various $\mathrm{NaOH}$ concentrations and immersion time periods $\left(40^{\circ} \mathrm{C}\right)$; (a) CMX; (b) AMX (N.M - Not mentioned). The photos of AMX were cited from Reference [18] and rearranged.

Figure $5 \mathrm{~b}$ shows the color change of AMX test pieces arranged from the results in a previous paper [18]. In the case of AMX, the pristine test piece was transparent, and no color change was observed after immersion in alkali-free deionized water. In contrast, when they were immersed in alkali solutions, the color gradually changed to yellow, orange, red, and violet, as the immersion time periods increased, and the test pieces eventually turned dark violet. The higher the $\mathrm{NaOH}$ concentration, the shorter the immersing time periods required for the change of color to dark violet.

If the hydroxyl ion concentration inside AMX held a constant value according to the calculation curve obtained using the Donnan theory and was almost independent of the external solution concentration, the color change of the test pieces did not depend on the alkali concentration of immersing solutions. However, the colors of the test pieces immersed in a $0.01 \mathrm{M} \mathrm{NaOH}$ solution for $3 \mathrm{~h}, 24 \mathrm{~h}$, and $168 \mathrm{~h}$ were yellow, orange, and red, respectively, and that immersed in a $1 \mathrm{M} \mathrm{NaOH}$ solution was dark violet. The $\mathrm{OH}$ concentration inside AMX decreased with a decline in the external concentration, as shown in Figure 2, which implies that the color change observations were consistent with the experimental results. 


\subsubsection{Chemical Analysis}

\section{ATR-FTIR Measurement}

As mentioned earlier, a clear difference was observed in the visual color changes of the CMX and AMX test pieces during the alkali immersion tests. In this section, we have discussed the reasons for these color changes to investigate the chemical structure change of the membranes before and after the immersion tests using ATR-FTIR by following the procedure discussed in prior literature [18,19].

Figure 6a shows the comparison of ATR-FTIR spectra of CMX test pieces immersed in $0.01 \mathrm{M}$, $0.1 \mathrm{M}$, and $1 \mathrm{M} \mathrm{NaOH}$ solutions for $168 \mathrm{~h}$. A spectrum before immersion is also shown here as pristine for comparison purposes. Before the ATR-FTIR measurement, the counter ions of the fixed charge were changed to $\mathrm{Na}^{+}$ions by immersing the test pieces in a $0.5 \mathrm{M} \mathrm{NaCl}$ solution for more than $24 \mathrm{~h}$.

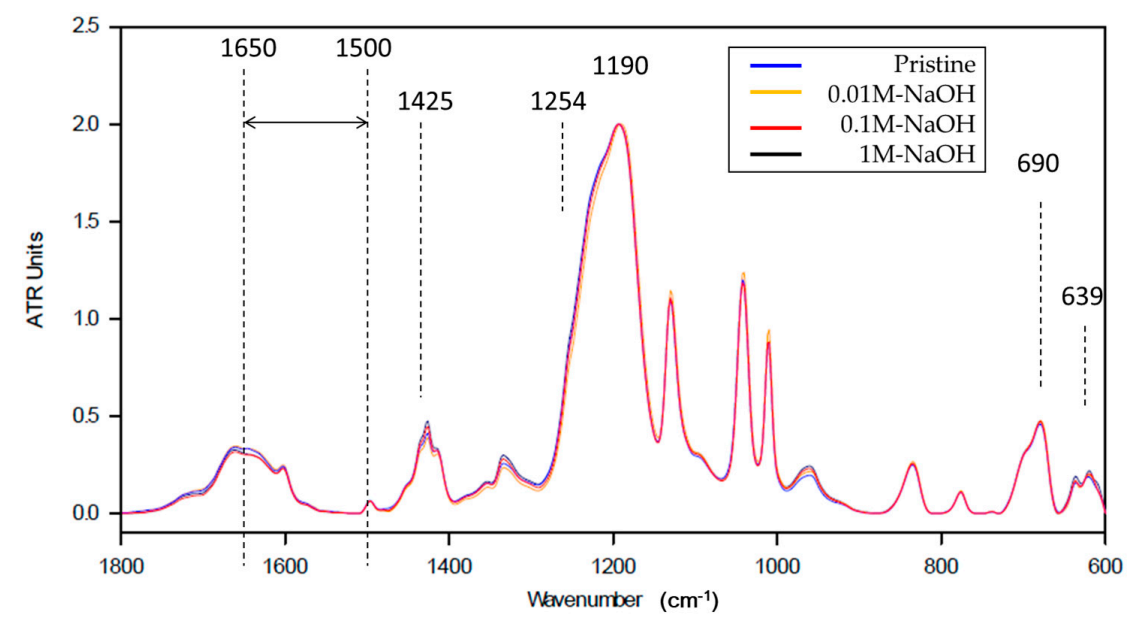

(a)

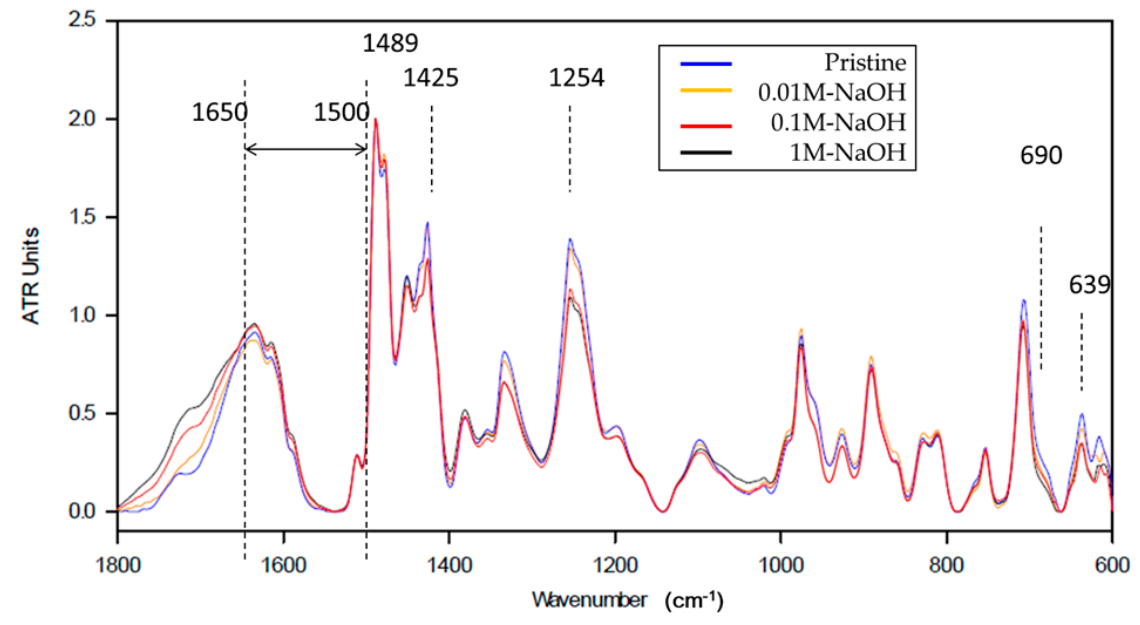

(b)

Figure 6. ATR-FTIR spectrum for (a) CMX and (b) AMX membranes before and after soaking in solutions with different $\mathrm{NaOH}$ concentrations.

For the quantitative discussion, we normalized the obtained spectra using the peak that originated from sulfonic acid group at $1190 \mathrm{~cm}^{-1}$, because an investigation of the IEC after and before the immersion tests clearly suggests that the decomposition of the sulfonic acid group has not occurred after the immersion, as shown in Appendix A. The other peaks were also attributed according to the previous literature [15]. 
In the case of the CMX immersed in lower $\mathrm{NaOH}$ concentrations, as expected, had peaks with respect to PVC, which were denoted by the bands at 639 and $690 \mathrm{~cm}^{-1}$, corresponding to $v(\mathrm{C}-\mathrm{Cl})$ stretching, those at $1254 \mathrm{~cm}^{-1}$ corresponding to $\delta\left(\mathrm{CH}_{2}\right)$ wagging, when the adjacent $\mathrm{C}$ atom included a chlorine atom, and those at $1425 \mathrm{~cm}^{-1}$ due to methylene scissor deformation from PVC, which did not show any change. Furthermore, the broadband intensity observed from $1500-1650 \mathrm{~cm}^{-1}$ with respect to the $v(C=C)$ vibration was not different from that of the pristine test piece. Thus, these spectra clearly indicated that no chemical reactions occurred when $\mathrm{CMX}$ was immersed in alkali solutions under $1 \mathrm{M}$ $\mathrm{NaOH}$ for $168 \mathrm{~h}$. These results agree with the visual observation results that indicate no color changes in CMX test pieces immersed under such conditions.

Figure $6 \mathrm{~b}$ shows the comparison of ATR-FTIR spectra of the AMX test pieces immersed in $0.01 \mathrm{M}$, $0.1 \mathrm{M}$, and $1 \mathrm{M} \mathrm{NaOH}$ solution for $168 \mathrm{~h}$ with that of the pristine test piece. In the case of AMX, the counter ions of the fixed charge groups were changed to $\mathrm{Cl}^{-}$ions before the ATR-FTIR measurement. As the aromatic rings of chloromethylstyrene (CMS) and divinyl-benzene (DVB) matrix in AMX were not decomposed after the alkali immersion tests [15], the spectra were normalized using the peak at $1489 \mathrm{~cm}^{-1}$, which was attributed to the aromatic ring breathing mode of CMS-DVB, followed by data analysis. In the case of $\mathrm{AMX}$ immersed in lower $\mathrm{NaOH}$ concentrations, the peaks originating from PVC at $639 \mathrm{~cm}^{-1}, 690 \mathrm{~cm}^{-1}, 1254 \mathrm{~cm}^{-1}$, and $1425 \mathrm{~cm}^{-1}$ apparently declined after the alkali immersion and gradually declined with an increase in the $\mathrm{NaOH}$ concentration. In addition, the intensity of the broadband at $1500-1650 \mathrm{~cm}^{-1}$ also increased. Moreover the broadband of $1650-1800 \mathrm{~cm}^{-1}$ increased significantly. The broad band of $1600-1800 \mathrm{~cm}^{-1}$ can be assigned to an absorbance of conjugated $\mathrm{C}=\mathrm{C}$ of the resulting polyenes [24]. Thus, these changes in the spectra clearly indicate that PVC dehydrochlorination and subsequent polyene formation have occurred, when AMX was immersed in alkaline solutions even with a lower $\mathrm{NaOH}$ concentration $(0.01 \mathrm{M})$. Therefore, these chemical structure changes cause the visual color change of AMX to be more drastic than that of CMX. In contrast, it is worth noting that the intensity of the peak at $1720 \mathrm{~cm}^{-1}$, attributed to the $(C=O)$ vibration, also increased, indicating the generation of a carbonyl group through PVC degradation.

XRF

Figure 7a,b show the effects of alkali concentration on normalized chlorine intensity using the XRF measurements of CMX and AMX test pieces, each immersed for $168 \mathrm{~h}$. In the case of CMX, no change in the normalized chlorine intensity was observed. In contrast, in the case of AMX, the normalized chlorine intensity decreases, as the $\mathrm{NaOH}$ concentration increased. The decrease in the chlorine intensity implies that the PVC dehydrochlorination increased with increasing $\mathrm{NaOH}$ concentrations. In particular, approximately $10 \%$ of PVC in AMX was lost when the test piece was immersed in $1 \mathrm{M}$ $\mathrm{NaOH}$ for $168 \mathrm{~h}$ at $40^{\circ} \mathrm{C}$.

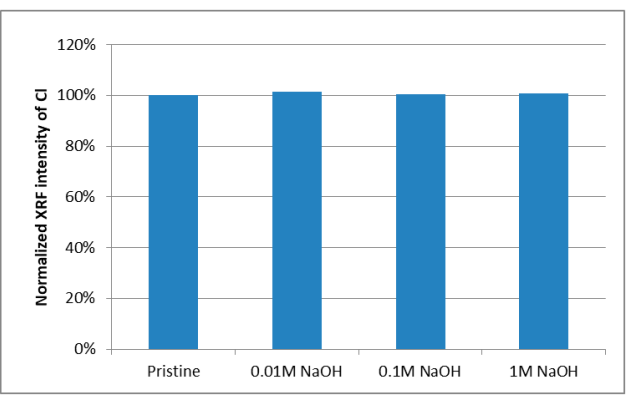

(a)

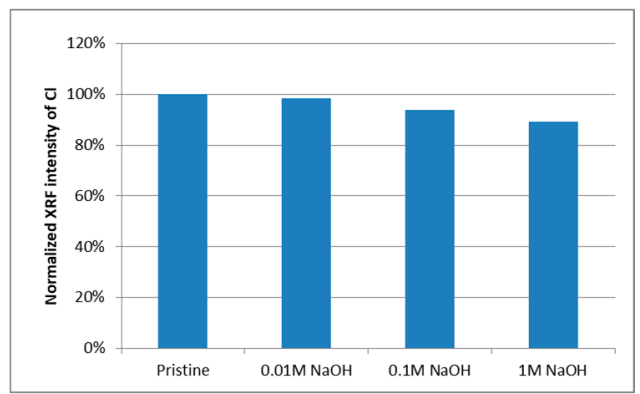

(b)

Figure 7. Normalized chlorine intensities obtained using XRF measurements before and after immersion in solutions of different alkali concentrations (a) CMX (b) AMX. 


\subsubsection{Characterization of Membrane Properties}

Figure 8 shows the normalized properties of $\mathrm{CMX}$ as a function of $\mathrm{NaOH}$ concentration and immersion time periods. For comparison, the data corresponding to AMX immersed in $1 \mathrm{M} \mathrm{NaOH}$ [18] were also included in these figures.
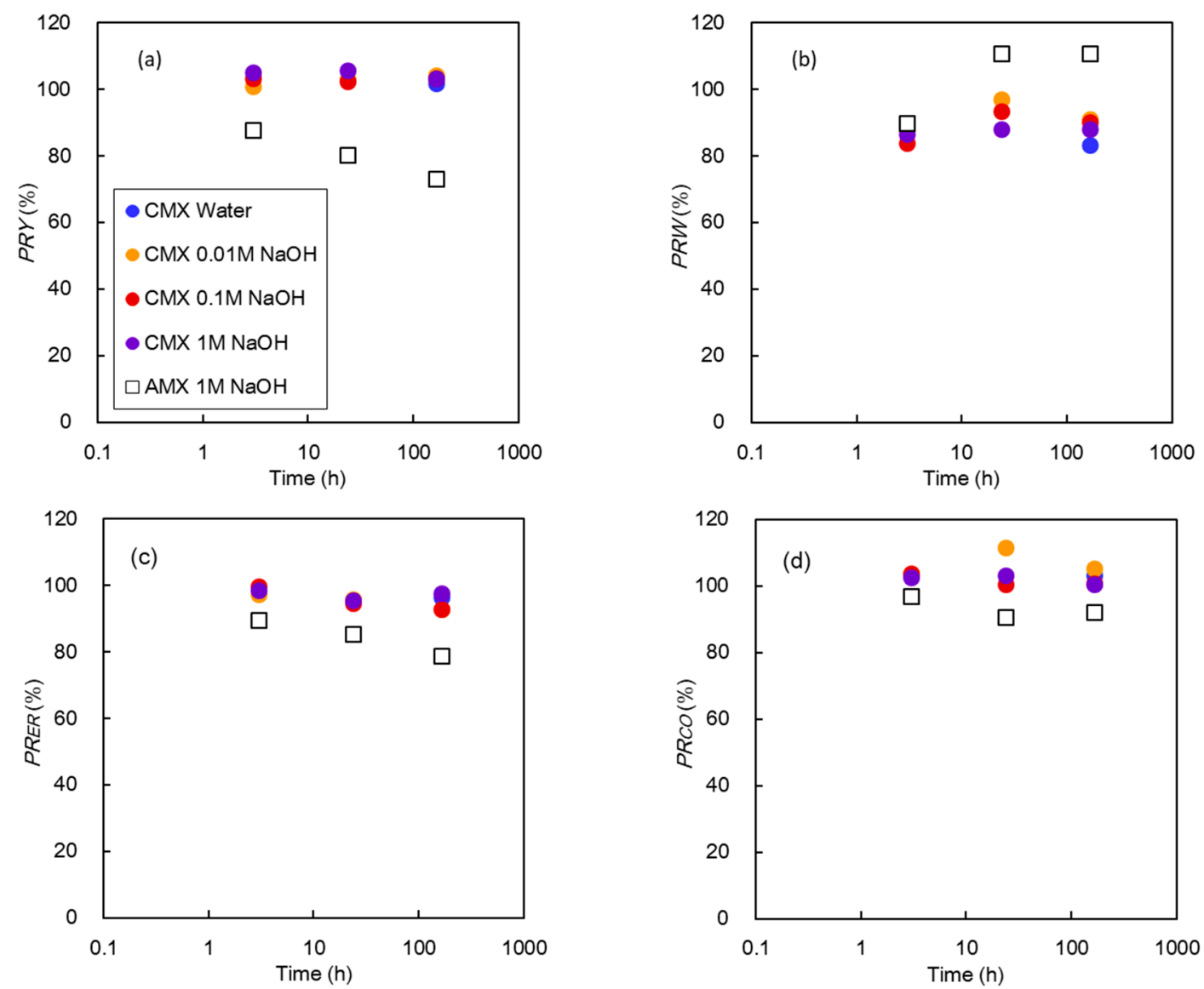

Figure 8. Normalized properties PR of CMX and AMX as a function of varying $\mathrm{NaOH}$ concentration and immersion time periods; (a): Young's Modulus $P R_{Y},(\mathbf{b})$ : water content $P R_{W}$, (c): electrical resistance $P R_{E R}$, and (d): co-ion rejection $P R_{C O}$.

In the case of AMX, a decrease in the normalized Young's modulus, an increase in the normalized water content, a decrease in the normalized electrical resistance and co-ion rejection with increasing immersion time periods were observed. In the case of AMX, hydroxyl ions caused the dehydrochlorination of PVC in the membrane, resulting in the formation of polyenes. This polyene formation caused a decrease in the Young's modulus and an increase in water content. An increase in water content implied an increase in the volume of water channels in the AEM, resulting in a decline in the electrical resistance and co-ion selectivity [18].

In the case of CMX, no change in the normalized Young's modulus, water content, electrical resistance and co-ion rejection was observed. This is because no changes were observed in the chemical structure of CMX during the low concentration immersing tests, as established by the ATR-FTIR spectra and XRF data.

As CMX showed no changes in its characteristics, it was not necessary to propose a nondestructive method for estimating the electrical characteristics, as was the case for AMX [18,19]. 


\subsection{Systematic Alkaline Immersion Test (High OH Concentration Test)}

\subsubsection{Color Change}

Figure 9 shows the color change of the test pieces of CMX, AMX, CMX precursor, and AMX precursor immersed in a $6 \mathrm{M} \mathrm{NaOH}$ solution for up to $168 \mathrm{~h}$ at $40{ }^{\circ} \mathrm{C}$. When the $\mathrm{CMX}$ test piece was immersed in a $6 \mathrm{M} \mathrm{NaOH}$ solution, the color change was observed in $24 \mathrm{~h}$. This indicated that even though the CMX was a CEM, it exhibited a color change after immersion in alkali solutions of high $\mathrm{OH}$ concentration for long time periods. In contrast, when the AMX test piece was immersed in a $6 \mathrm{M}$ $\mathrm{NaOH}$ solution, it immediately turned dark violet, within $3 \mathrm{~h}$, and the color further deepened as the immersion time periods increased. While AMX showed a drastic color change from transparent to dark violet, and CMX exhibited a color change from yellow to orange, no change was observed in the appearance of both CMX precursor and AMX precursor. The CMX precursor contained a styrene and di-vinyl-benzene matrix, while the AMX precursor comprised a chloromethylstyrene and di-vinyl benzene matrix. The former was provided by sulfonic acid groups by the sulfonation reaction, while the latter was provided quaternary ammonium groups by the quaternization reaction with trimethylamine to produce a CEM and an AEM, respectively. The water content of both the precursors was almost zero, because the matrix with no ion-exchange groups was hydrophobic. Hence, the $\mathrm{OH}$ ions could not permeate inside the matrix of the two precursors, thereby preventing the PVC dehydrochlorination from occurring even during the severe alkali immersion test conducted with a high $\mathrm{OH}$ concentration for longer time periods.

\subsubsection{Chemical Analysis}

\section{ATR-FTIR Measurement}

Figure 10a shows the comparison of ATR-FTIR spectrum of the CMX test piece immersed under severe conditions (6 M NaOH solution for $168 \mathrm{~h}$ ) with that of the pristine test piece. The obtained spectrum was also normalized as there was no decomposition of sulfonic acid group even in the $6 \mathrm{M}$ $\mathrm{NaOH}$ case, as shown in Appendix $\mathrm{A}$. In the case of higher $\mathrm{NaOH}$ concentrations, the band belonging to the $(\mathrm{C}-\mathrm{Cl})$ stretching band of $639 \mathrm{~cm}^{-1}$ had declined marginally, and the band at $1600-1700 \mathrm{~cm}^{-1}$, which originated from the conjugated $(\mathrm{C}=\mathrm{C})$ formation, increased marginally, as compared to those of the pristine test piece. Therefore, these chemical structures changed from the proposed PVC dehydrochlorination and subsequent polyene formation, which had a minimal extent under severe immersion conditions. Therefore, the minimal color change of CMX under severe conditions, shown in Figure 6, was possibly due to polyene formation through PVC dehydrochlorination.

Figure $10 \mathrm{~b}$ shows the comparison of ATR-FTIR spectrum of the AMX test piece immersed in severe conditions ( $6 \mathrm{M} \mathrm{NaOH}$ solution for $168 \mathrm{~h}$ ) with that of the pristine test piece. The bands at $639,690,1254$, and $1425 \mathrm{~cm}^{-1}$, corresponding to PVC, significantly declined. The broad band from $1500-1650 \mathrm{~cm}^{-1}$ corresponding to $(C=C)$ vibration, and $1650-1800 \mathrm{~cm}^{-1}$ corresponding to the conjugated $(\mathrm{C}=\mathrm{C})$ vibration significantly increased, compared to those in the case of lower $\mathrm{NaOH}$ concentration. Therefore, although the color changes of the AMXs immersed in both higher and lower $\mathrm{NaOH}$ concentrations for $168 \mathrm{~h}$ appeared to be saturated (the colors in both these cases are dark violet), the PVC degradation and subsequent polyene formation further progressed with increasing $\mathrm{NaOH}$ concentrations. This result also agrees with our previous result, which indicates that the membrane performance of $\mathrm{AMX}$ declines further with increasing $\mathrm{NaOH}$ concentrations, even after the complete change of color to dark violet [18].

In addition, the intensity of the peak at $1720 \mathrm{~cm}^{-1}$, attributed to the $(C=O)$ oscillation, also increased significantly. 


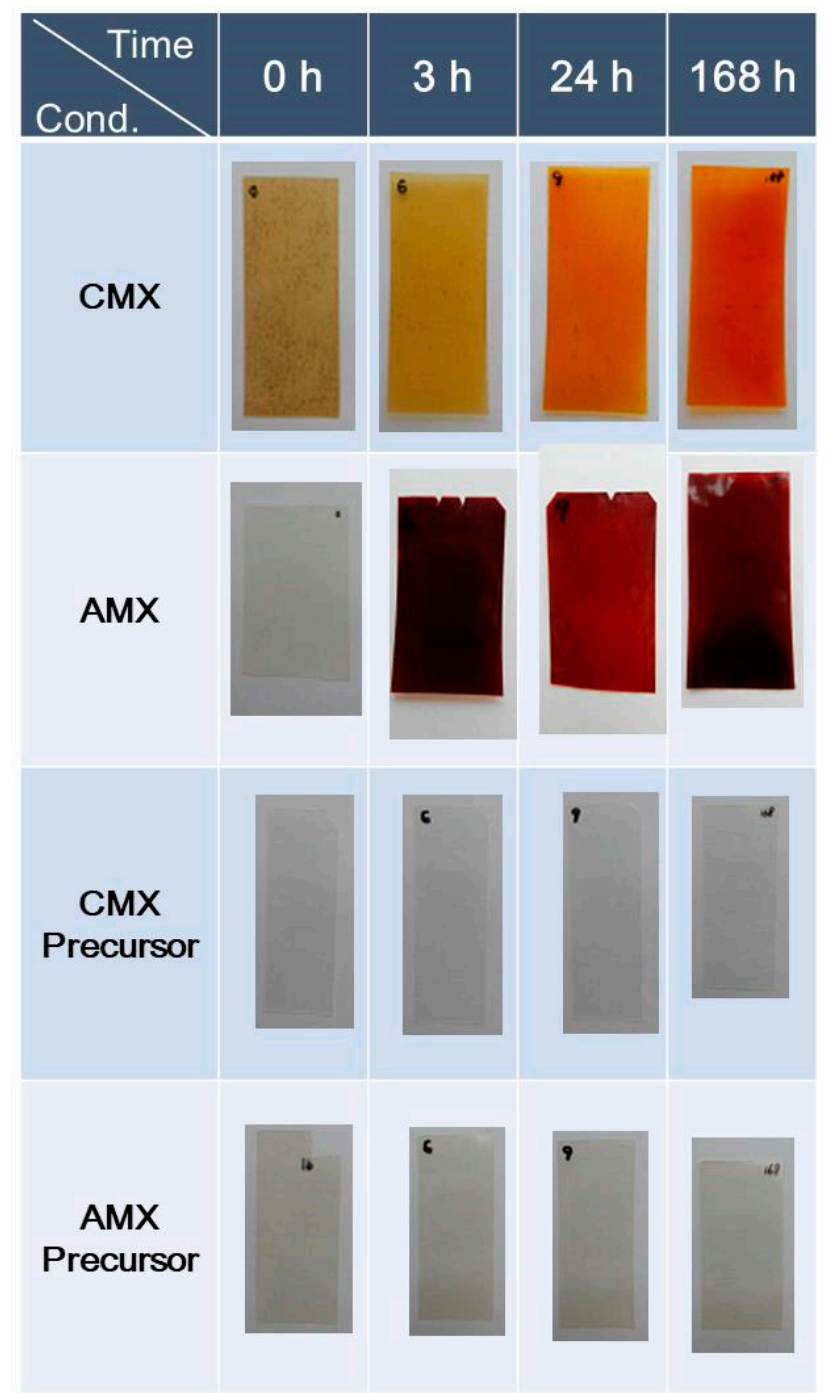

Figure 9. Color change in various test pieces with respect to $6 \mathrm{M} \mathrm{NaOH}$ concentration and varied immersion time periods $\left(40^{\circ} \mathrm{C}\right)$.

\section{XRF Measurement}

Figure 11a,b show the effects of alkali concentration on normalized chlorine intensity using the XRF measurements of CMX and AMX test pieces, each immersed in $6 \mathrm{M} \mathrm{NaOH}$ for $168 \mathrm{~h}$. In the case of CMX, no change in the normalized chlorine intensity was observed. This will probably be because $\mathrm{XRF}$ could not detect the minimal change in the chlorine content. In contrast, in the case of AMX, the normalized chlorine intensity decreases, as the $\mathrm{NaOH}$ concentration increased. Approximately $17 \%$ of PVC in AMX was lost.

The normalized chlorine intensities of the CMX precursor and AMX precursor are shown in Figure $11 \mathrm{c}, \mathrm{d}$, respectively. It was observed from these figures that the intensity values did not change at all before or after the immersion tests. 


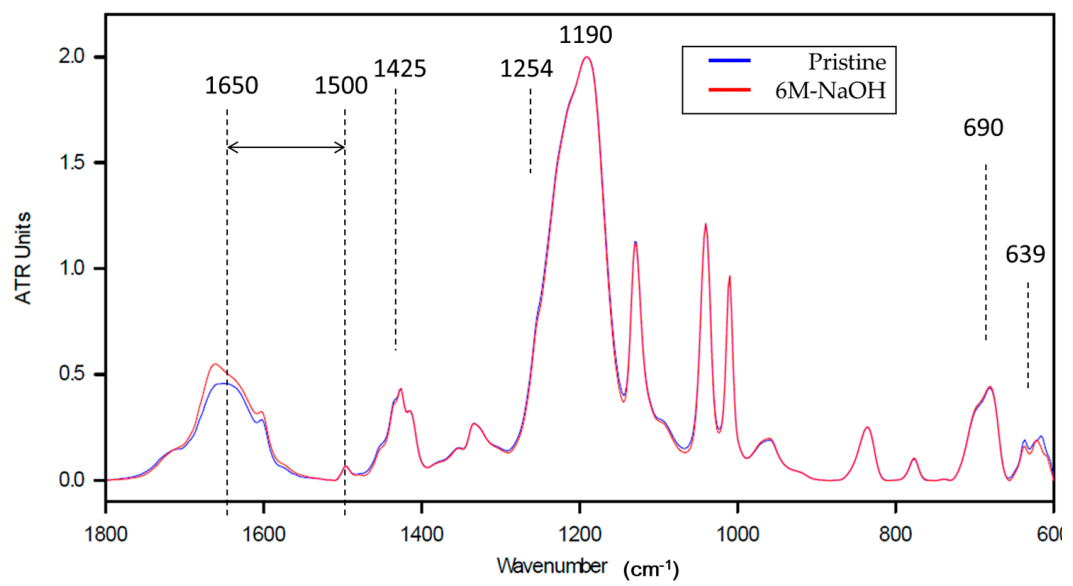

(a)

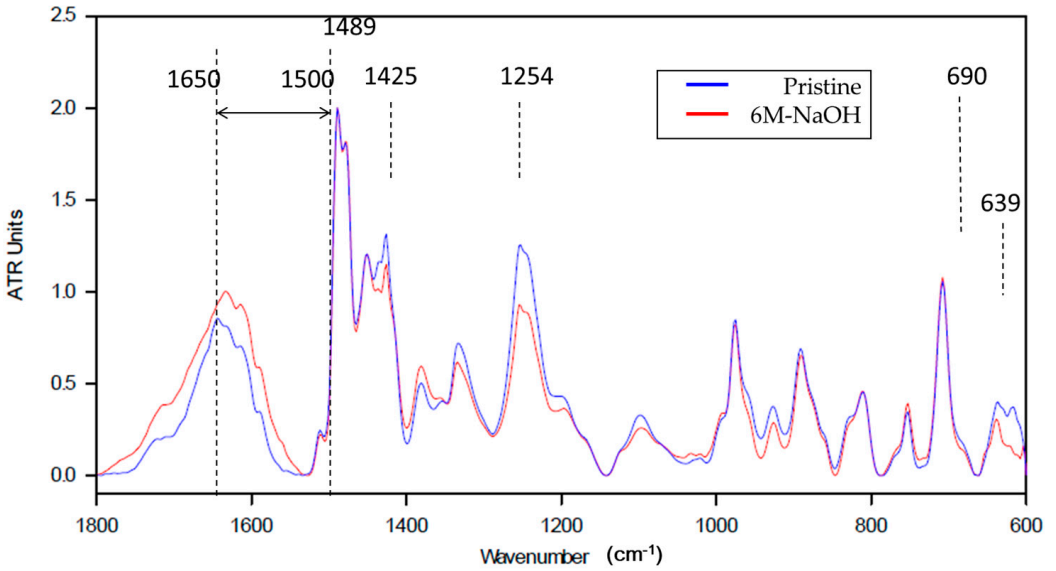

(b)

Figure 10. ATR-FTIR spectrum for (a) CMX and (b) AMX membranes before and after soaking in severe conditions (6 M NaOH solution for $168 \mathrm{~h}$ ).

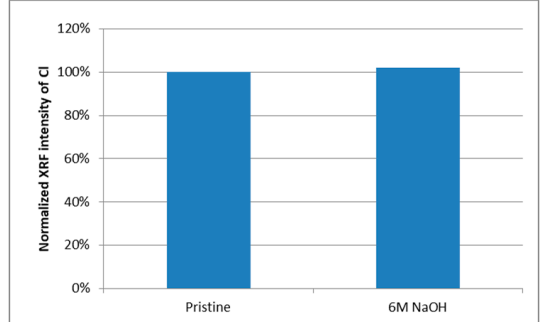

(a)

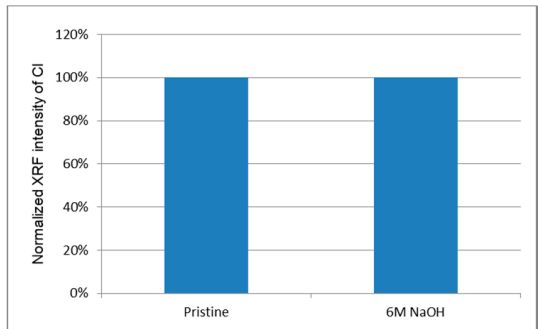

(c)

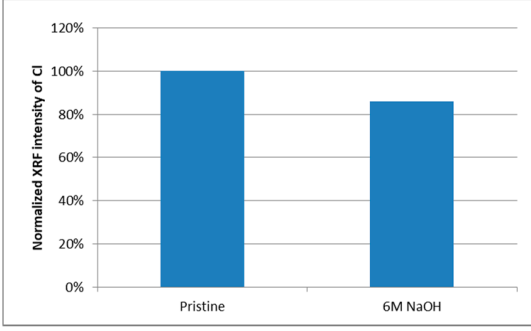

(b)

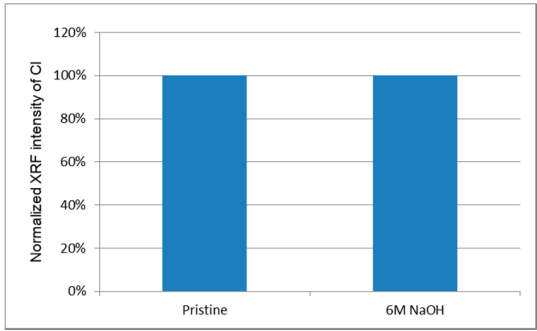

(d)

Figure 11. Normalized chlorine intensities obtained using XRF measurements before and after immersion in solutions of different alkali concentrations. (a) CMX, (b) AMX, (c) CMX precursor, and (d) AMX precursor. 


\subsection{Discussion}

The results of the chemical analysis of CMX and AMX immersed in alkali solutions are summarized as follows.

AMX:

In the ATR-FTIR measurement, the decrease in the peak derived from PVC degradation and the increase in the peak derived from polyene formation were observed. These changes in the peaks increased, as the $\mathrm{NaOH}$ concentration increased. In the XRF measurement, the chlorine intensity decreased, as the $\mathrm{NaOH}$ concentration increased. These results indicated that the dehydrochlorination of PVC occurred in AMX.

The equation of nucleophilic attack of hydroxide ions is expressed in Scheme 1, called the "E2 elimination reaction". Hydroxyl ion pull out $\beta$ hydrogen from PVC, at the same time the chloride ion is eliminated and forms a double bond [22].

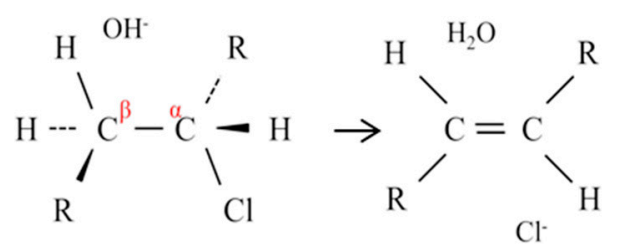

Scheme 1. The equation of nucleophilic attack of hydroxide ions (the "E2 elimination reaction").

In the ATR-FTIR spectra of AMX, the increase in the broadband intensity at $1700-1800 \mathrm{~cm}^{-1}$ indicated the generation of carbonyl groups during the alkali immersion test. The formation of the carbonyl band at $1779 \mathrm{~cm}^{-1}$ was observed due to sodium hypochlorite attack [14]. However, to the author's knowledge, carbonyl formation in PVC degradation because of alkali attack has not been reported in the previous literature $[11,12,14,15]$. Therefore, the mechanism of carbonyl formation should be investigated in the future.

CMX:

In the ATR-FTIR measurement, no change was observed in the peak derived from PVC during the immersing tests with up to $1 \mathrm{M} \mathrm{NaOH}$, and no change was observed in the chloride intensity values obtained using the XRF measurement. However, when CMX was immersed under severe conditions (6 M NaOH solution for $168 \mathrm{~h}$ ), a color change was observed, and the peak indicating the formation of polyene was obtained, but no decrease in chlorine intensity was confirmed by XRF. This will probably be because XRF could not detect the minimal change in the chlorine content. As shown in Appendix A, no change was observed in the IEC of CMX. These observations imply that not much change was observed in the chemical structure of CMX due to alkaline attack.

The dehydrochlorination reaction of PVC in CMX only occurred under severe alkali immersing conditions, such as high $\mathrm{NaOH}$ concentrations and long immersing time periods. The dehydrochlorination reaction of PVC scarcely occurred in CMX and cannot be explained by only the low $\mathrm{OH}$ concentration inside CMX due to the Donnan equilibrium.

Figure 12 shows a schematic diagram of the distribution of ions inside IEMs in the alkali immersion tests. In the case of the AEMs shown in Figure 12a, quaternary ammonium groups are the positively-charged ones that are fixed with the membrane matrix containing PVC. When the external alkali concentration is almost equal to the fixed charge density, the concentration of the counter-ions (hydroxide ions) in the water phase inside the membrane will be almost equal to that of the cations as the co-ions of the fixed charged groups. However, there will be more hydroxide ions than the cations around the positively-charged groups fixed with the membrane matrix. Hence, the hydroxyl ions can easily attack PVC chains of the membrane matrix. However, in the case of CEM, sulfonic acid groups 
such as the negatively-charged ones are fixed with membrane matrix, as shown in Figure 12b. Even under the same conditions as the AEM case, there will be more cations than the hydroxide ions around the negatively-charged groups fixed with the membrane matrix. Hence, it will be more difficult for hydroxyl ions to attack PVC chains of the membrane matrix than in the case of AEM. This is the main reason why the dehydrochlorination reaction does not easily occur in CMX.

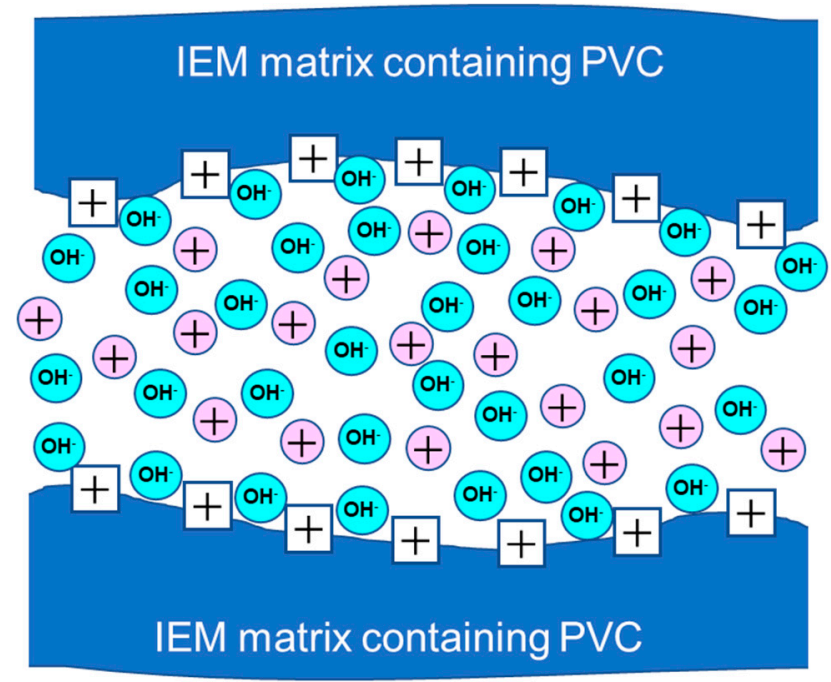

(a) AEM

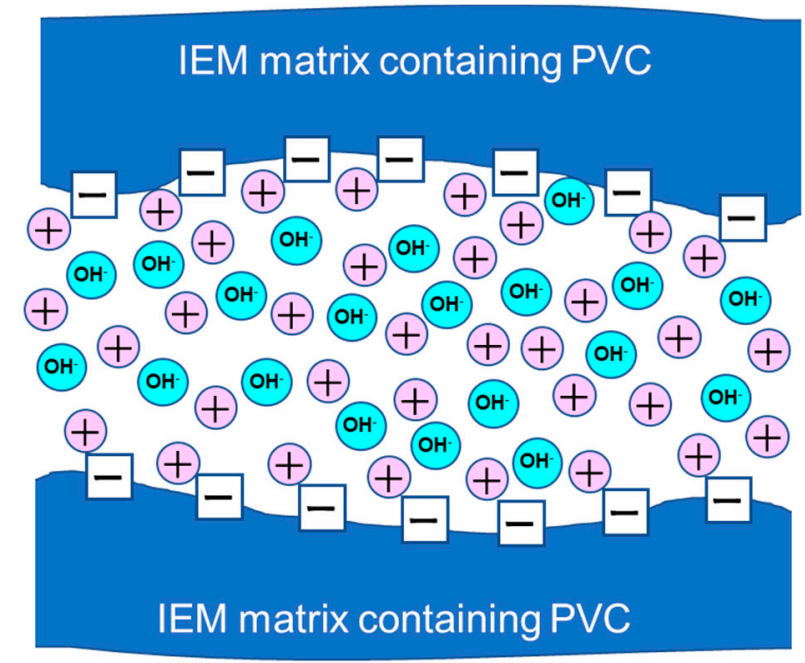

(b) CEM

Figure 12. Schematic diagram of the distribution of ions inside IEMs containing PVC. (a) AEM; (b) CEM.

Vasquez et al. reported that the quaternary ammonium salt in the AEM membrane acts as a catalyst, and dehydrochlorination of PVC with hydroxide ions results in the formation of a polyene sequence [15]. Our immersion tests in severe conditions (6 M NaOH solution for $168 \mathrm{~h}$ ) revealed that CMX, without any quaternary ammonium groups, changed its color and ATR-FTIR spectrum of CMX indicates that PVC dehydrochlorination and subsequent polyene formation occurred. Therefore, not only AEMs, but also CEMs with a PVC matrix, will be deteriorated by alkali, depending on the conditions. High concentrated hydroxide ions around the positively-charged groups fixed with the matrix will facilitate the alkali degradation of IEMs. One of the ways to avoid alkali degradation of IEMs is to prepare IEMs without PVC materials.

In the future, we will conduct CMX alkali immersion tests at high temperatures and high alkali concentrations to confirm the above hypothesis. 


\section{Conclusions}

In this research, to understand the deterioration mechanism of IEMs containing PVC as the backing and binder, systematic experiments were conducted using CMX, which is a commercially available CEM containing PVC in the backing and binder, under various alkali concentrations and immersing time periods at $40{ }^{\circ} \mathrm{C}$. We investigated the changes in the chemical structure and membrane properties of CMX before and after the immersion tests to compare the results with those of a commercial $\operatorname{AEM}(\mathrm{AMX})$.

In these experiments, no color change and no membrane properties change was observed up to a concentration of $1 \mathrm{M} \mathrm{NaOH}$ in the case of CMX. However, when immersed in $6 \mathrm{M} \mathrm{NaOH}$, which is close to its fixed charge density, for a week, the yellowish membrane turned slightly orange. An analysis of this discolored test piece using ATR-FTIR suggested minimal polyene formation. However, no loss of chlorine was observed in the XRF analysis. These results were compared with those of AMX, as reported in prior papers $[17,18]$. In the case of $\mathrm{AMX}$, the transparent membrane turned deep violet, and the color change rate increased with an increase in the alkali concentration. The ATR-FTIR analysis indicated that polyene was formed, while the XRF analysis indicated that chlorine was reduced, and PVC was dehydrochlorinated.

ATR-FTIR spectra of the AMX indicated that polyene, as well as the carbonyl groups, were formed through the PVC dehydrochlorination, although the formation mechanism is still unclear. A detailed analysis of PVC dehydrochlorination in an AEM containing PVC is required.

Based on the aforementioned discussion, we propose the mechanism of the differences in alkali degradation in the case of CMX and AMX as follows:

According to the Donnan equilibrium theory, even if CMX and AMX are immersed in $\mathrm{NaOH}$ solutions of similar concentrations, which is less than the fixed charge concentration, the hydroxide ion concentration inside CMX is significantly lower than that inside the AMX. This low OH concentration in CMX during the alkali immersion test is a factor of difference with respect to degradation.

The dehydrochlorination reaction of PVC in CMX only occurs under severe alkali immersing conditions: high $\mathrm{NaOH}$ concentrations and long immersing time periods. In such scenarios, the $\mathrm{OH}$ concentration inside CMX is almost equal to that inside AMX. From these results, it is clear that the dehydrochlorination reaction of PVC scarcely occurs in CMX, not only because of the low $\mathrm{OH}$ concentration inside CMX due to the Donnan equilibrium, but also because the negatively charged sulfonic acid group repels the negatively charged hydroxyl ion so that the hydroxyl ion cannot access the PVC that makes up the IPN. This is the main reason why the dehydrochlorination reaction does not easily occur in CMX.

Author Contributions: M.H. and S.D. conceived and designed the experiments; S.D., N.T. and Y.K. did the experiments, and analyzed the data; S.D. and M.H. wrote the paper and made discussions including researching about previous literature. All authors have read and agreed to the published version of the manuscript.

Funding: This research received no external funding.

Acknowledgments: The authors would like to thank Akio Kamimura of Yamaguchi university and Ikuo Taniguchi of International Institute for Carbon-Neutral Energy Research (WPI-I $\left.{ }^{2} \mathrm{CNER}\right)$, Kyushu University for their scientific advice on chemical reactions.

Conflicts of Interest: The authors declare no conflict of interest.

\section{Appendix A}

Figure A1 shows the normalized ion-exchange capacity (IEC) PIEC of CMX as a function of varying $\mathrm{NaOH}$ concentration and immersion time periods at $40^{\circ} \mathrm{C}$. No change is observed in normalized IEC of CMX. 


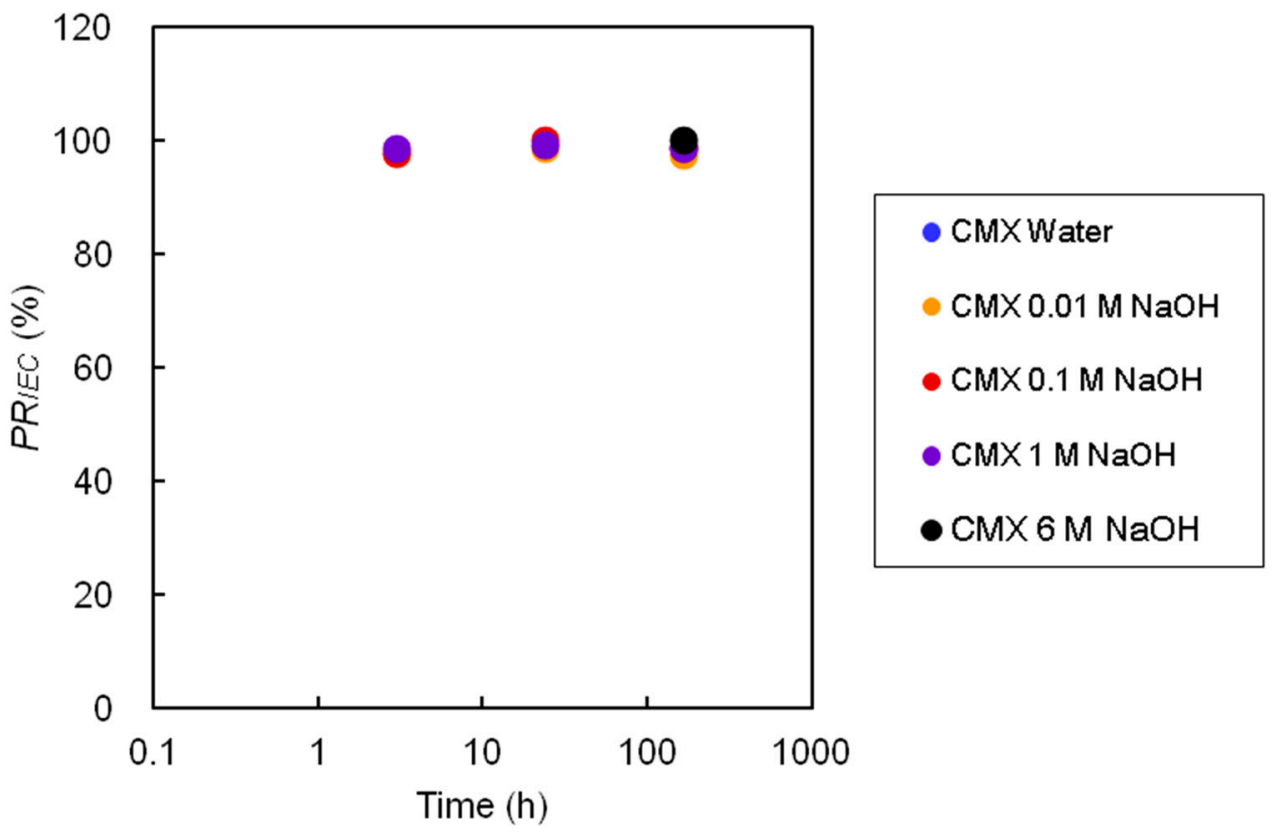

Figure A1. Normalized ion-exchange capacity (IEC) PIEC of CMX as a function of varying $\mathrm{NaOH}$ concentrations and immersion time periods at $40{ }^{\circ} \mathrm{C}$.

\section{References}

1. Tanaka, Y. Ion exchange membranes, Preparation, Characterization, Modification and Application; Royal Society of Chemistry: London, UK, 2004; p. 3.

2. Xu, X.; He, Q.; Ma, G.; Wang, H.; Nirmalakhandan, N.; Xu, P. Selective separation of mono- and di-valent cations in electrodialysis during brackish water desalination: Bench and pilot-scale studies. Desalination 2018, 428, 146-160. [CrossRef]

3. Selvaraj, H.; Aravind, P.; Sundaram, M. Four compartment mono selective electrodialysis for separation of sodium formate from industry wastewater. Chem. Eng. J. 2018, 333, 162-169. [CrossRef]

4. Babilas, D.; Dydo, P. Selective zinc recovery from electroplating wastewaters by electrodialysis enhanced with complex formation. Sep. Purif. Technol. 2018, 192, 419-428. [CrossRef]

5. Mei, Y.; Tang, C.Y. Recent developments and future perspectives of reverse electrodialysis technology: A review. Desalination 2018, 425, 156-174. [CrossRef]

6. Tufa, R.A.; Pawlowski, S.; Veerman, J.; Bouzek, K.; Fontananova, E.; di Profio, G.; Velizarov, S.; Crespo, J.G.; Nijmeijer, K.; Curcio, E. Progress and prospects in reverse electrodialysis for salinity gradient energy conversion and storage. Appl. Energy 2018, 225, 290-331. [CrossRef]

7. Mehdizadeh, S.; Kuno, M.; Yasukawa, M.; Kawabata, Y.; Higa, M. Evaluation of Energy Harvesting from Discharged Solutions in a Salt Production Plant by Reverse Electrodialysis (RED). Desalination 2019, 467, 95-102. [CrossRef]

8. Abo, T.; Mehdizadeh, S.; Kakihana, Y.; Yasukawa, M.; Higa, M. Power generation performance of a pilot-scale reverse electrodialysis (RED) stack. Bull. Soc. Sea Water Sci. Jpn. 2019, 73, 96-97.

9. Mehdizadeh, S.; Yasukawa, M.; Abo, T.; Kakihana, Y.; Higa, M. Effect of spacer geometry on membrane and solution compartment resistances in reverse electrodialysis. J. Membr. Sci. 2019, 572, 271-280. [CrossRef]

10. Ghalloussi, R.; Garcia-Vasquez, W.; Bellakhal, N.; Larchet, C.; Dammak, L.; Huguet, P.; Grande, D. Ageing of ion-exchange membranes used in electro-dialysis: Investigation of static parameters, electrolyte permeability and tensile strength. Sep. Purif. Technol. 2011, 80, 270-275. [CrossRef]

11. Ghalloussi, R.; Garcia-Vasquez, W.; Chaabane, L.; Dammak, L.; Larchet, C.; Deabate, S.V.; Nevakshenova, E.; Nikonenko, V.; Grande, D. Ageing of ion-exchange membranes in electrodialysis: A structural and physicochemical investigation. J. Membr. Sci. 2013, 436, 68-78. [CrossRef] 
12. Garcia-Vasquez, W.; Dammak, L.; Larchet, C.; Nikonenko, V.; Pismenskaya, N.; Grande, D. Evolution of anion-exchange membrane properties in a full scale electrodialysis stack. J. Membr. Sci. 2013, 446, 255-265. [CrossRef]

13. Ghalloussi, R.; Chaabane, L.; Larchet, C.; Dammak, L.; Grande, D. Structural and physicochemical investigation of ageing of ion-exchange membranes in electrodialysis for food industry. Sep. Purif. Technol. 2014, 123, 229-234. [CrossRef]

14. Garcia-Vasquez, W.; Ghalloussi, R.; Dammak, L.; Larchet, C.; Nikonenko, V.; Grande, D. Structure and properties of heterogeneous and homogeneous ion-exchange membranes subjected to ageing in sodium hypochlorite. J. Membr. Sci. 2014, 452, 104-116. [CrossRef]

15. Garcia-Vasquez, W.; Dammak, L.; Larchet, C.; Nikonenko, V.; Grande, D. Effects of acid-base cleaning procedure on structure and properties of anion-exchange membranes used in Electrodialysis. J. Membr. Sci. 2016, 507, 12-23. [CrossRef]

16. Mizutani, Y.; Yamane, R.; Ihara, H.; Motomura, H. Studies of ion exchange membranes. XVI. The preparation of ion exchange membranes by the "Paste Method". Bull. Chem. Soc. Jpn. 1963, 36, 361-366. [CrossRef]

17. Mizutani, Y.; Yamane, R.; Motomura, H. Studies of ion exchange membranes. XXII. Semicontinuous preparation of ion exchange membranes by the "Paste Method". Bull. Chem. Soc. Jpn. 1965, 38, 689-694. [CrossRef]

18. Doi, S.; Yasukawa, H.; Kakihana, Y.; Higa, M. Alkali attack on anion exchange membranes with PVC backing and binder: Effect on performance and correlation between them. J. Membr. Sci. 2019, 573, 85-96. [CrossRef]

19. Doi, S.; Kinoshita, M.; Yasukawa, M.; Higa, M. Alkali attack on anion exchange membranes with PVC backing and binder: II Prediction of electrical and mechanical performances from simple optical analyses. Membranes 2018, 8, 84. [CrossRef]

20. Zabolotsky, V.I.; Nikonenko, V.V. Effect of structural membrane inhomogeneity on transport properties. J. Membr. Sci. 1993, 79, 181-198. [CrossRef]

21. Sarapulova, V.; Shkorkina, I.; Mareev, S.; Pismenskaya, N.; Kononenko, N.; Larchet, C.; Dammak, L.; Nikonenko, V. Transport characteristics of fujifilm ion-exchange membranes as compared to homogeneous membranes AMX and CMX and to heterogeneous membranes MK-40 and MA-41. Membranes 2019, 9, 84. [CrossRef]

22. Higa, M.; Tanaka, N.; Nagase, M.; Yutani, K.; Kameyama, T.; Takamura, K.; Kakihana, Y. Electrodialytic properties of aromatic and aliphatic type hydrocarbonbased anion-exchange membranes with various anion-exchange groups. Polymer 2014, 55, 3951-3960. [CrossRef]

23. Tanaka, N.; Nagase, M.; Higa, M. Preparation of aliphatic-hydrocarbon-based anion-exchange membranes and their anti-organic-fouling properties. J. Membr. Sci. 2011, 384, 27-36. [CrossRef]

24. Danno, T.; Kondoh, H.; Furuhata, K.I.; Miyasaka, K. Synthesis, Structure, and Properties of Conjugated Polyene Films by Dehydrochlorination of PVC Films. J. Appl. Polym. Sci. 1984, 29, 3171-3184. [CrossRef]

(C) 2020 by the authors. Licensee MDPI, Basel, Switzerland. This article is an open access article distributed under the terms and conditions of the Creative Commons Attribution (CC BY) license (http://creativecommons.org/licenses/by/4.0/). 